19. Chasnoff, J., And Solomon, S. (1938): Journ. Lab. and Clin. Med., 23, 887, 894 .

20. Taran, A., and Lipstein, S. (1939): Journ. Lab. and Clin. Med., 24, 479 .

\title{
OBSERVATIONS ON RHEUMATIC DISEASES UNDER WAR CONDITIONS*
}

\section{By OSWALD SAVAGE}

Since the outbreak of the German air offensive against this country an opportunity has arisen to observe patients in the various stages of rheumatic diseases who have been living under active war conditions.

The intermittent bombing of London which for long spells has been of nightly occurrence has brought both mental and physical stress which would tend to cause the onset of rheumatic conditions in those susceptible and the aggravation of the symptoms of those already suffering.

The attendance at both clinics where I have worked has shown an increase during the last year despite the large evacuation from London and the fact that many of those requiring treatment have come irregularly owing to the difficulties of travel and the fear that the clinic might have been destroyed. The only decrease has been in the type of patient with rather vague rheumatic pains and no clinical abnormality who responded to many types of treatment for a time and then passed on to another clinic. These were usually of a nervous temperament and may have taken advantage of the evacuation schemes.

The feature most directly affecting the health of Londoners is the necessity of the nights spent in shelters. The two most detrimental elements are the shortage of sleep and the cold and damp often prevalent. Rheumatic subjects are particularly vulnerable.

I have questioned patients on the types of shelters they use and have seen representative examples.

In the suburbs the Anderson shelter is most common, and as these shelters are sunk into the ground it is impossible to exclude

\footnotetext{
* Received for publication March 24, 1941.
} 
the damp. When water once enters these shelters it is extremely difficult to expel it.

In many parts of London where the houses have basements one in each street is appropriated, strengthened and inhabited communally. Though not as exposed as the Anderson shelters, there is a lingering humidity owing to the particular house and the surrounding dwellings often being empty because of evacuation.

The concrete turf-covered shelters constructed to accommodate 50 to 180 people are little used at night, as they are so cold and cramped.

Large public shelters, mostly in the East End, holding hundreds or even thousands, have been filled to capacity, as they are safe and there are few basements in that area. The conditions at the beginning of the Blitzkrieg were appalling. The occupants slept either on the damp stone floors, on a mattress which became saturated or in deck chairs. Added to this acute discomfort there was a complete lack of sanitation, a fotid atmosphere and constant noise. Since the Horder Commission sweeping reforms have been carried out: sanitation installed, bunks constructed, first-aid posts established and damp areas walled off.

Tube shelters are probably the safest and driest of all. The atmosphere, however, is oppressive, and until recently there have not been enough bunks for all, so that people have had to sleep in unnatural positions.

Because of the vast national effort a large proportion of the population have changed to more rigorous occupations. Women have undertaken jobs usually done by men and many have taken up regular work for the first time, therefore bringing unaccustomed muscles into use. Increased production and A.R.P. duties have lengthened working hours and added an extra strain on physique.

I have seen examples of the various types of rheumatic disease and met one new condition. This is a bilateral painful œdema of the feet which has been termed "shelter feet." It is apparently the result of sleeping in a sitting position, often in a deck chair, with the knees flexed. The œedema and painful distension of the skin are secondary to impaired venous return.

The remaining cases have mainly fallen into the grouping of fibrositis, the rheumatoid type of arthritis and osteo-arthritis. 


\section{Fibrositis}

This comprises the majority and may be divided into two groups: firstly, occupational, due to muscular strains; secondly, environmental, due to sleeping in cramped positions.

(a) Occupational.-The chief muscle groups affected have been those of the forearms and thighs, with the pains referred to the regions of the wrist and knee joints. On questioning, the patients relate that they have used either their arms with some unaccustomed tool or hand lathe, or their legs in driving a heavy vehicle, or a pedal to turn a machine.

On examination the pain has been reproduced by a particular opposed movement, and small areas of acute tenderness have been found, presumably where there has been a slight tear in the muscle. These cases have responded well to injection of local anæsthetic into the tender areas, followed by remedial exercises.

(b) Environmental.-Here the muscles most frequently in. volved have been the trapezii and glutei, the former from sitting for long periods with the shoulders leaning against a cold, damp wall, and the latter from sitting either on stone floors or saturated cushions.

In the case of trapezial involvement the pain was referred either up to the neck or occiput or down the arms, while in the latter the area of reference was down the back of the thigh, causing sciatica.

On examination there has been a diffuse tenderness on palpation of the muscle, but less pain on movement than in the previous group. A number of nodules were occasionally found, but single areas of exquisite tenderness on palpation have been rare.

Treatment of these cases is more difficult, but in general they have responded steadily to heat followed either by massage or to ionisation with histamine.

I noted that in both types of fibrositis the blood sedimentation rate (Westergren) has been normal.

\section{The Rheumatoid Type of Arthritis}

It is a clinical assumption that many factors play a part in the ætiology of the rheumatoid type of arthritis. So many patients attribute the onset to some emotional upset that there 
is evidently a large psychological element in the production of this disease. The present disturbed conditions caused by air attacks on London would therefore tend to result in the increase of rheumatoid arthritis both from fresh cases and from relapses.

It is too early to be certain whether this has occurred, but the indication that at both clinics the number of cases of the rheumatoid type of arthritis has increased while the population of London has diminished would point to this probability being a fact.

I have questioned patients as to what they attributed their onset or relapse, and in a large number of cases they have replied that it was due to bombing, either being bombed themselves or the loss of a relative or friend. "You see, it was the shock that brought it on," was a common answer.

The psychological state of these patients has also sometimes reacted in their favour, for the excitement of doing dangerous work and being kept on the alert has in many cases resulted in a steady improvement in their general and local condition. Many of the patients, noticeably the women, have been employed on A.R.P. duties such as ambulance drivers or wardens, working long hours and in key positions. It has been striking how theyo have been able to keep at their work through an arduous winter, often having no time to come to the clinic other than for the weekly injection of gold. They say that they feel better and show an increase in weight and an improvement in the joint movements, together with a fall in sedimentation rate. In fact, some have expressed surprise that they have managed so well. This improvement may, of course, be due entirely to the gold salt therapy, but I believe the fact that they are doing an essential national service has been a helpful stimulus.

A certain number of patients suffering from rheumatoid arthritis require hospital treatment at some period. Their health deteriorates and they lose weight so rapidly that in spite of supervision and treatment as out-patients they are unable to carry on. Under the stress of war this point seems to be reached more rapidly than in time of peace, and I have found that whereas formerly many patients were reluctant to submit to hospital treatment and would struggle on, sometimes for months, they are now only too willing to be admitted within a few weeks of the onset.

Another probable factor in the causation of rheumatoid 
arthritis is focal infection. Luckily there has not been the increase in such infections that was expected, so there has been no opportunity to study this.

\section{OSTEO-ARTHRITIS}

Patients suffering from this degenerative condition have fared badly in London during the winter. Many of them had been enabled to keep about and their pain had been controlled by repeated courses of physiotherapy at hospitals and clinics. These they required more especially in the winter months.

As a result of the war some clinics have had to close for periods and staffs have been depleted. In addition, travel to treatment centres, always a problem for these patients, has become even more difficult. In consequence they have suffered more than any other group.

\section{Conclusion}

Rheumatic sufferers as a class are often accused of being difficult patients to treat because they are of a nervy temperament.

It has been noticeable how they have vindicated themselves during the past critical months, often being bombed out of their homes and having to work longer hours than formerly. They have accepted treatment gratefully and kept on cheerfully at their work, often rather to their own surprise, and have certainly played their part in the national effort.

It would appear that there has been an increase in rheumatism, at any rate in London, and that there will be greater numbers requiring treatment. With the vast improvements in shelter conditions their lot may be alleviated, but it is essential that clinics for advice should be kept going to aid them. 